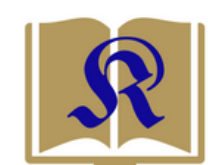

KURIOS
KURIOS

(Jurnal Teologi dan Pendidikan Agama Kristen)

ISSN 2615-739X (print), 2614-3135 (online)

Vol. 5, No. 2, Oktober 2019 (139-150)

http://www.sttpb.ac.id/e-journal/index.php/kurios

\title{
Diam atau Bersuara: Tafsir terhadap Kisah Safira dan Izebel dari Perspektif Feminis
}

\author{
Asnath Niwa Natar \\ Fakultas Teologi, Universitas Kristen Duta Wacana. Yogyakarta \\ asnathnatar@yahoo.com
}

\begin{abstract}
Women are always placed as second class under their husbands in the patriarchal culture. The wife belongs to the husband who must obey her husband, no matter what, whether it is good or bad. This makes women unable to show a critical manner and attitude for fear of the risks they will face. Such attitude has also happened since the time of the Bible, which could be unconsciously imitated by the wives today. Thus, a reinterpretation from a feminist perspective will be made to contribute ideas and insight for women or wives nowadays and to see how the roles of wives towards their husbands. The two biblical narratives to be raised are Interpretations of Acts 5: 1-11 and 1 Kings 21: 1-29.
\end{abstract}

\begin{abstract}
Abstrak
Dalam budaya Patriarkhi, perempuan selalu ditempatkan pada posisi nomor dua di bawah suaminya. Istri adalah milik suami yang harus patuh pada suaminya, entah itu perbuatan yang baik atau yang tidak baik. Kondisi ini membuat kaum perempuan atau istri tidak mampu menunjukkan sikap kritis karena takut pada resiko yang akan dihadapi. Sikap istri yang seperti ini ternyata juga sudah terjadi sejak jaman Alkitab, yang bisa secara tidak sadar ditiru oleh para istri saat ini. Sehubungan dengan hal ini, maka akan dilakukan tafsir ulang dari perspektif feminis untuk memberikan sumbangan pemikiran bagi para perempuan atau istri bagaimana peran istri yang seharusnya terhadap suaminya. Kedua kisah istri dalam Alkitab yang akan diangkat adalah Tafsiran Terhadap Kis. 5:1-11 dan 1 Raj. 21:1-29
\end{abstract}

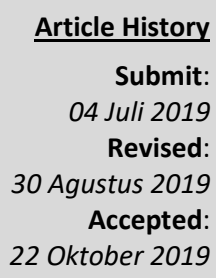

Keywords (kata kunci):

feminist;

Jezebel;

patriarchy;

Sapphira;

wife;

feminis;

istri;

Izebel;

patriarki;

Safira;

https://doi.org/10.30995/kur.v4i1.117

\section{Pendahuluan}

Dalam budaya Jawa terdapat filosofi "swarga nunut neraka katut" dalam relasi suami istri, di mana istri patuh, setia dan mengikuti suami kemana pun dia pergi, ke surga menumpang dan ke neraka pun ikut. Pandangan ini dikaitkan dengan posisi suami sebagai kepala rumah tangga dan istri hanya mengikuti saja. Kalau rumah tangga baik, istri juga akan 
baik, tetapi bila rumah tangga jelek maka istri juga menjadi jelek dan katut ke neraka. ${ }^{1}$ Dengan kata lain, jika suami melakukan perbuatan baik, istri akan ikut merasakan hasilnya. Sebaliknya, jika suami melakukan hal-hal yang tak pantas maka istri pun ikut menanggung aibnya. Sikap ini dilakukan tanpa protes apalagi memberontak. Hal ini didukung pula oleh sosok perempuan (istri) ideal yang diibaratkan seperti lima jari tangan manusia. Ibarat jempol, perempuan harus mengabdi kepada laki-laki (suami). Ibarat telunjuk, perempuan harus menuruti perintah laki-laki (suami). Ibarat penunjul (jari tengah), perempuan harus mengunggulkan laki-laki (suami) bagaimanapun keadaaannya. Ibarat jari manis, perempuan harus selalu bersikap manis. Ibarat jari jejenthik, perempuan harus berhati-hati, teliti, rajin, dan terampil melayani laki-laki (suami). ${ }^{2}$ Namun ungkapan Swarga nunut, neraka katut, sebenarnya bukan berasal dari budaya Jawa, melainkan dari agama Islam, yaitu dari Hadis nabi (Dalam Musnad Ahmad hadis nomor 18233). Di situ dikatakan bahwa suatu ketika ada seorang perempuan datang kepada Nabi untuk mengadukan kelakuan suaminya yang tidak baik, lalu Nabi menasihati agar bersabar karena bagaimana pun dia (suami) adalah surgamu dan nerakamu. ${ }^{3}$ Suami adalah imam dan istri harus patuh mengikuti suaminya baik dalam melakukan perbuatan yang baik ataupun tidak baik. Akibatnya perempuan senantiasa ditempatkan pada posisi korban, baik ketika ia sendiri yang berbuat salah maupun ketika ia harus menanggung kesalahan suaminya.

Pemahaman ini dipengaruhi oleh budaya patriarkhi dan androsentris. Patriarkhi (dari Bahasa Yunani pater $=$ bapak, arkhe $=$ kekuasaan) adalah laki-laki berkuasa dalam semua aspek kehidupan dan mempertahankan kuasa sebagai milik yang sah, baik melalui Lembaga masyarakat, harta maupun pengetahuan. ${ }^{4}$ Atau dengan kata lain, kekuasaan bapak (laki-laki) yang mendominasi, mensubordinasi dan mendiskriminasikan kaum perempuan (badan, seksualitas, peran dan status) dalam keluarga, gereja dan masyarakat. Hal ini nampak dalam ungkapan: "Ketika masih kanak-kanak perempuan adalah milik ayahnya, ketika dewasa ia milik suami, dan ketika tua, ia milik anak laki-lakinya". Patriarki bukan menunjuk kepada laki-laki secara individual melainkan dalam kategori konsep suatu sistem berpikir, bertindak, yang mendominasi perempuan. Patriarki bisa juga dimaknai sebagai suatu sistem bertingkat yang telah dibentuk oleh suatu kekuasaan yang mengontrol, mendominasi atau menguasai pihak lain (mereka yang lemah, miskin, tidak berdaya, minoritas, berkulit hitam atau berwarna dan perempuan). Sedangkan Androsentris (Yun. aner-andros= laki-laki, Latin centrum $=$ pusat). Laki-laki yang menjadi pusat karena ia dipandang sebagai yang pertama dan penting, penentu apa yang baik dan benar. ${ }^{5}$

${ }^{1}$ H.B. Nugroho, "Perempuan Dalam Budaya Jawa", dalam: Jurnal Teologi Gema Duta Wacana, Ed.55 Tahun 1999, p. 47

${ }^{2}$ Lihat A.P. Murniati, "Perempuan Indonesia dan Pola Ketergantungan", dalam: Budi Susanto, dkk (Eds.), Citra Wanita dan Kekuasaan (Jawa), Yogyakarta, Kanisius \& Lembaga Studi Realino, 1992, p. 24.

${ }^{3}$ Nur Huda, "Melacak Akar Ketidakadilan Gender Dalam Islam. Telaah Terhadap Hadis Suwargo Nunut, Neroko Katut", dalam: Erwati Azis, dkk (Eds.), Relasi Jender dalam Islam, Surakarta, Pusat Studi Wanita STAIN, 2002, p.132, 137-138.

${ }^{4}$ Marie Claire Barth-Frommel, Hati Allah Bagaikan Hati Seorang Ibu, Jakarta, BPK, 2003, p. 9. Lihat juga Sylvia Walby, Patriarki, Yogyakarta, Jalasutra, 2014, p. 9.

${ }_{5}$ Marie Claire Barth-Frommel, Hati Allah ....., p. 9. Lihat juga Sylvia Walby, Patriarki, Yogyakarta, Jalasutra, 2014, p. 28-29 
Budaya Israel dan budaya sekitarnya juga dipengaruhi oleh budaya patriarkhi. Istri adalah milik suami, bisa diceraikan, dan tidak mempunyai hak warisan (Kel. 20:17, Ul. 24:1-5, Bil. 27:1-11). Nasibnya ada di tangan suaminya dan dia tidak mempunyai hak apa-apa. ${ }^{6}$ Kaum perempuan adalah subordinat dan istri memanggil suaminya dengan sebutan: ba'al (sang majikan) atau adon (tuan). ${ }^{7}$ Ini menunjukkan bahwa istri harus tunduk kepada majikan atau pemiliknya.

Pertanyaannya adalah apakah istri memang harus mengikuti apapun yang dilakukan oleh suaminya, dan apa dampaknya? Sehubungan dengan hal itu, saya akan mengangkat kisah Safira, istri Ananias, dalam Kis. 5:1-11 dan kisah Izebel, istri Ahab dalam 1 Raj. 21:1-29.

\section{Metode}

\section{Tafsiran Terhadap Kisah Para Rasul 5:1-11 dan 1 Raja-Raja 21:1-29}

Kedua kisah ini akan ditafsirkan dari perspektif teologi feminis dengan menggunakan metode hermeneutik kecurigaan (Investigasi) dan analisis kritis dari Elisabeth S. Fiorenza. ${ }^{8}$ Metode ini akan menolong pembaca untuk tidak menerima begitu saja apalagi meniru apa yang tertulis dalam Alkitab, melainkan perlu meneliti atau menginvestigasi latarbelakang konteks budaya yang bersifat patriarkhi dan androsentris. Prinsip dasar dari hermeneutik kecurigaan (investigasi) adalah bahwa teks dan diskursus terjadi tidak dalam ruang kosong, melainkan dalam konteks relasi kekuasaan, dimana ada pihak yang mendominasi dan pihak yang didominasi. Bahasa teks cenderung andro-kyriosentris (berpusat pada laki-laki dan pada tuan) namun nampak sebagai sesuatu yang alamiah atau wajar, sehingga mendorong pembaca untuk berpikir yang sama dan menjadi tidak kritis. Karena itu, dalam hermeneutik kecurigaan, seorang penafsir harus selalu mengawali pembacaan dengan kritis dan asumsi (kecurigaan awal) tentang unsur relasi kekuasaan yang ada dalam teks dan melakukan investigasi. Penafsir akan menginvestigasi fungsi ideologi dan kyriosentris yang mendominasi dalam teks yaitu dengan memperhatikan gramatika teks kyriosentris yang maskulin, sudut pandang, komentar, tafsiran, prasangka, dan sistem nilai. Selain itu, penafsir juga akan mencari potonganpotongan dan garis-garis kisah yang mungkin hilang, terhilang atau sengaja dihilangkan dari teks, dan mengapa bagian itu hilang. ${ }^{9}$ Apakah ada maksud tertentu dalam rangka kekuasaan dan dominasi atas dasar gender atau tidak?

Beberapa teks dalam Alkitab bersifat menindas dan berpengaruh dalam ajaran gereja serta mempengaruhi sikap terhadap perempuan, termasuk larangan perempuan untuk menjadi pelayan atau pendeta antara lain: Kej. 3:1-24 tentang Hawa sebagai penyebab manusia jatuh dalam dosa. Kej. 16:1-16; 29:30-30:24 yang menyebutkan bahwa tugas utama perempuan adalah melahirkan anak-anak dan menyenangkan suami. Hak. 19, tentang gundik yang diperkosa oleh penduduk kota demi melindungi tuannya, seorang Lewi, yang kemudian dipotong-potong menjadi dua belas bagian oleh suaminya sendiri. Kej. 16: 6-9 adalah kisah Hagar yang ditindas oleh Sarai demi mendapatkan anak laki-laki bagi suami mereka

\footnotetext{
${ }^{6}$ David Atkinson, Rut, Jakarta, Yayasan Komunikasi Bina Kasih/OMF, 2000, p.61.

${ }^{7}$ Philip J. King \& Lawrence E. Stager, Kehidupan Orang Israel Alkitabiah, Jakarta, BPK, 2012, p. 60.

${ }^{8}$ Lebih jelasnya bisa membaca Elisabeth Schuessler Fiorenza, Wisdom Ways. Introducing Feminist Biblical Interpretation, Maryknoll, New York, Orbis Books, 2001, p. 165-191.

9 Asian Women's Resource Centre for Culture and Theology, Membaca Alkitab dengan Mata Baru, Yogyakarta, Asian Women's Resource Centre for Culture and Theology dan PERUATI, 2013.
} 
Abraham. Kedua perempuan ini menjadi korban dari budaya patriarkhi. 2 Sam. 13:1-39 adalah kisah Tamar yang diperkosa oleh saudara tirinya Abnon. Est. 1: 17-22 berisi peringatan agar perempuan menghormati suaminya dan tidak boleh melawan supaya tidak bernasib sama seperti Wasti. 1 Kor 14:33-35 dan 1 Tim 2: 12-15 dimana perempuan harus diam dalam pertemuan jemaat, bila ingin menanyakan sesuatu, tanyalah pada suami di rumah. Perempuan juga tidak boleh mengajar dan memerintah laki-laki. Phyllis Trible menyebut teks Kej. 16:1-16; 21:9-21: Hagar; 2 Sam. 13:1-22: Tamar; Hak. 19:1-30: Perempuan tanpa nama; Hak. 11:29-40: Putri dari Jefta, sebagai texts of terror karena sangat merendahkan perempuan dan bersifat terror yang menakutkan. ${ }^{10}$

Penindasan dan diskriminasi terhadap perempuan bukan hanya karena Alkitabnya yang memang dihasilkan dalam konteks budaya patriarkhi, namun juga oleh karena penafsiran beberapa teks yang dilakukan dari perspektif maskulin dan menghasilkan ketidakadilan dan penindasan. Beberapa teks tersebut adalah: Kej 1 dan 2: Perempuan diciptakan sesudah lakilaki karena itu perempuan lebih rendah dari laki-laki. Ef. 5: Perempuan harus menempatkan diri di bawah suami dan tunduk pada suami. Kejadian 2, Ef. 5 dan I Kor. 14:33-35 sering dipakai oleh Bapa-bapa gereja untuk menundukkan perempuan di bawah suami dan menghalangi perempuan menjadi imam atau pendeta. ${ }^{11}$

Hermeneutik investigasi akan menolong pembaca untuk tidak menggunakan Alkitab sebagai alat penindasan, namun sebaliknya sebagai sarana penyelamatan dan pembebasan bagi kaum perempuan.Sehubungan dengan kondisi Alkitab dan adanya penafsiran yang bias gender, maka saya akan menafsirkan teks Kis. 5:1-11 tentang Safira dan 1 Raj. 21:1-29 tentang Isebel dengan hermeneutik kecurigaan (investigasi) yaitu dengan cara meragukan atau mempertanyakan teks untuk memahami apa dan bagaimana posisi perempuan dalam budaya patriarkhi.

\section{Pembahasan}

\section{Safira (Istri Ananias): Kisah Para Rasul 5:1-11}

Kisah Para Rasul. 3:1-5:42, berbicara tentang kisah "Kepemimpinan Apostolis di Yerusalem" yang dapat dibagi atas:

(a) 3:1-11: kuasa nama Yesus

(b) 3:12-26: panggilan pertobatan dan keselamatan Israel

(c) 4:1-30: konfrontasi para elit Yerusalem

(d) 4:31-5:15: hasil pencurahan Roh yang kedua.

Kis. 4:36-5:11 menguraikan contoh positif dan negatif kepemilikan bersama. Pada Kis. 4:35-37, figur Yusuf Barnabas diuraikan secara positif dan Kis. 5:1-11 diuraikan figur Ananias dan Safira secara negatif. Hasil pencurahan Roh yang kedua (ayat 31) menjelaskan bagaimana sikap dan perilaku pengikut Yesus tentang kehidupan bersama sebagai komunitas, tidak hanya dalam iman dan pengharapan melainkan juga dalam kepemilikan harta (sharing), secara khusus bagi sesama yang membutuhkan. Komunitas ini tidak mengenal perbedaan kelas, dan membagikan kekayaan yang mereka miliki kepada semua anggota komunitas.

\footnotetext{
${ }^{10}$ Phyllis Trible, Texts of terror, Literary-feminist readings of biblical narratives, USA, SCM Press, 1992.

${ }^{11}$ Heike Walz, .... Nicht Mehr maenlich und weiblich...? Ekklesiologie und Geschlecht im Oekumenischen Horizont, Frankfurt a.M, Lembeck, 2006, p. 372.
} 
Perikop berisi undangan untuk berbagi dalam pengorbanan yang menekankan kesucian komunitas dan peringatan agar tidak berbohong pada para hamba Allah yang mengetahui hati semua orang (1:24). Ananias dan Safira ingin bergabung dengan komunitas Allah namun tetap memelihara otonomi pribadi mereka dari otoritas Tuhan. ${ }^{12}$

Penipuan dalam persekutuan umat Allah bukanlah narasi baru dalam Alkitab. Perjanjian Lama mencatat kisah Akhan yang mengambil barang-barang yang dikuduskan (Yos. 7) yaitu jubah indah buatan Sinear, dua ratus syikal perak dan sebatang emas seberat lima puluh syikal (Yos. 7:21) yang menimbulkan hukuman berat di lembah Akhor (Yos. 7:26). Gema narasi Akhan ini kemungkinan besar menjadi bahan bagi penulis kitab Kisah Para Rasul dengan pemikiran teologis bahwa dosa dapat mengacaukan dan mengganggu koinonia, bahkan dalam dunia primitif, sebagai komunitas ideal. Peristiwa mati tiba-tiba juga sudah pernah terjadi bagi para imam di hadapan Allah (Im. 10:1-5). Gehazi adalah tokoh yang dapat mengingatkan pembaca Lukas (penulis Kisah Para Rasul) di dalam peristiwa pemuridan nabi yang sangat tamak akan harta (2 Raj. 5:20-27), meskipun bukan hukuman mati. Selain itu, Lukas juga sering mengkonfrontasikan kuasa iblis dengan kuasa Tuhan (Luk. 11:20) dan pada kisah Ananias dan Safira ia mengkonfrontasikan gereja dengan jemaat yang hatinya dikuasai iblis (Kis. 5:3; bdk. Luk. 22:3). Melalui metode penulisan kisah yang demikian, ia mengembangkan perikop ke dalam tema kepemilikan, bahkan sengaja mempertentangkannya dengan kemunafikan. ${ }^{13}$

Paparan tentang harta yang memperdaya hati manusia telah disebutkan Lukas dalam Injil terkait dengan pengkhianatan Yudas Iskariot, dan kisah Ananias menjadi paralel dengan Yudas Iskariot (hati yang dikuasai iblis) dalam Luk. 22:3 dan Kis. 5:3 dan mereka bersekongkol demi uang (Luk. 22:4-6 dan Kis. 5:9). Aspek lain yang perlu mendapat perhatian adalah adanya persengkongkolan suami isteri (Kis. 5:2) yang menjadi alasan mendapat hukuman yang sama.

Pada bagian pertama teks (Kis. 5:1-4) Ananias menjadi pelaku, namun di bagian kedua (Kis. 5:8-9) dalam ucapan Petrus, Safira ikut sebagai pelaku. Ananias memutuskan, merencanakan dan melakukan penggelapan sebagian uang dan Safira ikut bermain dengan menjadi kaki tangan Ananias. Melalui tindakannya ini ia ikut aktif dalam tindakan penggelapan tersebut. Pertanyaannya mengapa Safira tidak mengatakan yang sebenarnya? Bisa jadi karena ia terperangkap dalam berbagai kekuatan, yaitu kelas, budaya patriarkhi dan kekaisaran. $^{14}$

Safira adalah seorang perempuan kaya, karena mereka memiliki tanah dan kemungkinan dari kelas atas, ${ }^{15}$ namun bisa jadi ikut menindas mereka yang miskin. ${ }^{16}$ Namun komunitas di mana ia menjadi anggotanya, hidup dalam sebuah solidaritas radikal dengan orang miskin dengan menggabungkan kekayaan yang mereka miliki. Sebenarnya Safira melakukan

\footnotetext{
${ }^{12}$ Uraian ini didasarkan pada Craig S. Keener, Acts 3:1-14:28. An Exegetical Commentary, Volume 2, Grand Rapids Michigan: Baker Academic, 2013, p. 263-277.

${ }^{13}$ Craig S. Keener, Acts 3:1-14:28.....p. 264-265

${ }^{14}$ Margaret Aymer, "Acts of the Apostles", dalam: Carol A. Newsom, Sharon H. Ringe \& Jaqueline E. Lapsley, Women's Bible Commentary, Philippines, Claretian Communications Foundation, 2016, p. 539.

${ }^{15}$ Nurseli Debora Manurung, "Kejujuran Sebagai Alat Melawan Korupsi (Kisah Para Rasul 5:1-11)", dalam Jurnal Sophia, No.1 Tahun 2016, p. 57.

${ }^{16}$ Margaret Aymer, "Acts of the Apostles"........p. 539
} 
tindakan positif dengan menyetujui penjualan tanah milik mereka. Dengan persetujuan tersebut, ia menolak untuk mengamankan harta yang menjadi bagiannya, yang sebenarnya sudah dijamin berdasarkan hukum Yahudi dan dengan kontrak, jika terjadi perceraian. Safira memberikan haknya sebagai istri untuk kepentingan masyarakat. Saat menjual, dia mengambil posisi aktif secara hukum. Tetapi apa yang terjadi kemudian menunjukkan sikap negatif, dimana ia pasif dan tunduk pada sistem patriarki. Jadi masalahnya bukan pada tindakan penjualan tanah secara bersama, tetapi pada penggelapan yang direncanakan dan direalisasikan oleh Ananias. Safira tahu itu tetapi ia terperangkap dalam pernikahan yang harus tunduk pada suami, ${ }^{17}$ karena ia adalah milik dari suaminya, sesuai dengan kebiasaan dan hukum masyarakatnya. Ia harus mengikuti atau patuh kepada suaminya. Mengatakan yang sebenarnya atau mengatakan bahwa suaminya adalah seorang pembohong adalah sebuah aib dan bisa diceraikan bahkan bisa mengancam nyawanya. Karena itu, ia berada di antara pilihan antara hidup nyaman di bawah budaya patriarkhi dan panggilan untuk bersolider dengan orang-orang miskin. ${ }^{18}$ Dan ia memilih untuk lebih berpihak pada kuasa patriarkhi.

Berkaitan dengan harta yang diserahkan kepada seorang pemimpin komunitas, sesungguhnya bukanlah hal baru dalam sejarah. Para pengikut Pythagoras dan Essene misalnya menjual harta milik mereka dan mempercayakan pengelolaan segala sumber daya yang ada kepada pemimpinnya. Jika seseorang hendak menjadi pengikut suatu komunitas secara penuh, maka ia harus melepaskan seluruh hartanya secara permanen kepada komunitas. Prinsip inilah yang berlaku umum pada masa awal kekristenan. ${ }^{19}$ Tidak berarti komunitas Kristen Yerusalem mengikuti dan mempraktekkan prinsip umum ini, sebab mereka tidak wajib memberi kepada komunitas. Tuntutan yang disampaikan kepada komunitas adalah sikap kedermawanan atau memberi dengan sukarela. ${ }^{20}$ Maksudnya, peristiwa yang terjadi pada Ananias dan Safira sebaiknya tidak dijelaskan sebagai suatu aksi dramatis Petrus, yang mempertontonkan kuasa dan menimbulkan ketakutan kepada khalayak. Teks eksplisit menekankan konflik antara iblis dengan Roh Kudus, bukan antara Petrus dengan Ananias (ay. 9: "Kata Petrus, Mengapa kamu berdua bersepakat untuk mencobai Roh Tuhan....”). Jika harus dikaitkan dengan Petrus, maka argumen untuk itu dapat dilihat dalam Luk. 22:31-32, di mana dinyatakan bahwa Petrus sendiri dicobai iblis, tetapi Yesus berdoa baginya untuk menguatkan saudara-saudaranya. Tugas itulah yang diterima oleh Petrus berhadapan dengan anggota komunitas yang hatinya dikuasai oleh iblis. Ananias tidak berdusta kepada komunitas atau manusia melainkan kepada Allah (5:4). Itulah yang tidak disadari oleh Ananias dan

${ }^{17}$ Band. Craig S. Keener, Acts 3:1-14:28.....p. 275. Teks ini menunjukkan betapa sulit dan hampir mustahil untuk hidup dalam Firman yang baik dari kerajaan Allah dalam dunia dan persekutuan gereja yang secara simultan dibentuk oleh budaya patriarki. Safira lebih memihak kepada suaminya daripada kepada hamba Tuhan, dalam hal ini Petrus.

${ }^{18}$ Margaret Aymer, "Acts of the Apostles", dalam: Carol A. Newsom, Sharon H. Ringe and Jacqueline E. Lapsley (Eds.), Women's Bible Commentary, Revised and Updated, Philipphines: Claretian Communications Foundation, 2016, p. 539

${ }^{19}$ Robert M. Grant, Early Christianity and Society: Seven Studies, San Fransisco: Harper \& Row 1977, p. 100; Markus Öhler, “Antikes Vereinswesen”, dalam: Klaus Scherberich (Ed.), Neues Testament und Antiken Kultur Band 2: Familie - Gesellschaft - Wirtschaft, Neukirchen-Vluyn: Neukirchener, 2011, p. 83. Peraturan yang berlaku di dalam suatu komunitas Kristen dapat dibaca pada beberapa naskah Qumran.

${ }^{20}$ Ferdinand Hahn, Theologie des Neuen Testaments. Bd. I: Die Vielfalt des Neuen Testaments, Tübingen: Mohr Siebeck, 2011, p. 574. 
peristiwa yang menimpa pasangan suami-isteri itu bukanlah pelanggaran sumpah. Etika komunitas yang telah terganggu oleh sikap pasangan itulah yang menjadi prioritas pemberitaan Lukas. Jadi sebenarnya Ananias dan Safira bisa saja tidak memberikan seluruh hasil penjualan mereka, karena itu adalah hak milik mereka. Para rasul tidak memaksakan hal ini (lih. Ayat 4). Persoalan yang muncul adalah, mereka tidak jujur alias berbohong dan tidak memberikan penjelasan apa-apa, juga ketika kesempatan untuk menjelaskan itu diberikan (ayat 8). Jadi, mereka dihukum bukan karena ketamakan mereka, melainkan karena kebohongan. ${ }^{21}$ Mereka bersikap seolah-olah sudah memberikan seluruh hasil penjualan, padahal tidak. Dan dengan cara seperti itu mereka menampilkan diri sebagai orang yang baik hati, dermawan, padahal tidak.

Teks sama sekali tidak menyebut adanya vonis dari Petrus sebagaimana banyak muncul dalam tafsiran yang beredar. Perkataan dan pernyataan dari Petrus juga sebaiknya tidak harus dipahami sebagai vonis, kutuk atau teror bagi Ananias dan Safira tetapi sebagai ungkapan profetis atau pernyataan ilahi. Tidak dapat disangkal bahwa Petrus bertindak sebagai agen Allah dan dengan posisi itu tentu Petrus tidak hendak memperlihatkan otoritas pribadinya di hadapan orang banyak. Ketakutan yang terjadi bagi banyak orang dalam tradisi Akitab dan Yahudi (post biblis) adalah fakta terhadap tindakan Allah (Ul. 13:11; 17:13; 19:20; 21:21; Bil. 16:34; 3 Makk. 7:14-15). Kematian yang seketika ini, sehingga tidak ada kesempatan untuk pertobatan, berkaitan dengan situasi jemaat awal yang ideal, yang menginginkan kemurnian iman tanpa dusta. Apalagi dusta kepada Roh Kudus yang bisa sangat fatal dan mengerikan.

Pertanyaan yang muncul dari peristiwa kematian Ananias dan Safira adalah mengapa Ananias segera dikuburkan sementara isterinya sendiri tidak hadir dalam peristiwa itu? Demikian juga penguburan Safira yang terkesan terburu-buru tanpa dihadiri pihak keluarga dan tidak ada ratapan kematian? Keener menjelaskan alasan utama terhadap pertanyaan ini berada pada makna baru keluarga di dalam gereja (bdk. Luk. 18:29-30). Keluarga di dalam komunitas Kristen awal di Yerusalem memiliki harta dan tanggung jawab bersama. Anggota komunitas lain memikul tanggung jawab bagi Ananias dan Safira, tidak hanya menguburkan tetapi juga menyediakan tanah wakaf (lih. Kis. 4:34). ${ }^{22}$ Dan ini adalah layanan terakhir dari komunitas terhadap mereka, kendati komunitas atau jemaat dilukai oleh tindakan Ananias dan Safira. Gereja tidak memberikan penghakiman, karena penghakiman adalah hak Allah.

Dari uraian di atas nampak bahwa kalau Ananias bersalah oleh karena keinginannya untuk menonjolkan diri (cari kehormatan), maka Safira bersalah untuk ketidakmampuannya menentukan nasib sendiri dan tidak berada di bawah kuasa suaminya, walau Petrus sudah memberikan kesempatan itu kepadanya. ${ }^{23}$ Ini tantangan bagi kaum perempuan untuk berani melawan dan tidak diam saja terhadap sikap suami yang salah. Kaum perempuan tidak boleh meniru sikap Safira, namun harus kritis dan melakukan perlawanan agar tidak dikutuk

21 J. Albert Harrill, "Divine Judment Against Ananias and Sapphira (Acts 5:1-11): A Stock Scene of Perjury and Death", dalam Journal of Biblical Literature, Volume 130, No. 2, Summer 2011, p. 369.

${ }^{22}$ Craig S. Keener, Acts 3:1-14:28.....p. 274

${ }^{23}$ Ivoni Richter Reimer, "Die Apostelgeschichte. Aufbruch und Erinnerung, dalam: Luise Schottroff und Marie-Theres Wacker, Kompendium Feministische Bibelauslegung, Guetersloh: Guetersloher Verlagshaus, 2007, p. 547-548. 
bersama dengan laki-laki (suami). Dengan cara demikian maka situasi mematikan seperti itu dapat dibalik, bukan subordinasi dan kediaman kaum perempuan, tetapi perlawanan.

Agar perempuan dapat mengambil langkah yang membebaskan seperti itu, maka dibutuhkan dukungan, tidak hanya dalam mengangkat harga diri perempuan dan penentuan nasib sendiri, tetapi juga dalam menunjukkan solidaritas kepada mereka melalui doa dan tindakan nyata dari gereja atau komunitas. Jika gereja gagal melakukan ini, maka dunia akan terus penuh dengan Safira-Safira yang lain, yang akan membungkam kebisuannya dari banyak Ananias di seluruh dunia, dan kematian pun akan terus terjadi.

\section{Izebel (Istri Ahab): 1 Raja-raja. 21:1-29}

Kendati Izebel bukan orang Yahudi, namun ia juga hidup dan dipengaruhi oleh budaya Patriarkhi, sama seperti Safira, namun sikap keduanya agak berbeda. Safira lebih banyak bungkam sedangkan Izebel lebih banyak bertindak, kemungkinan karena dia berasal dari kalangan atas (anak Etbaal, raja orang Sidon). Sebagai putri seorang raja, ia memiliki kuasa yang lebih dari pada perempuan-perempuan yang lain, apalagi kemudian ia menjadi istri seorang raja, yaitu Ahab. Kendati Izebel dan Ahab sama-sama dari kalangan atas, namun secara gender dalam budaya patriarkhi, posisi Izebel berada di bawah suaminya.

Kisah tentang Ahab dan Izebel sudah dimulai dalam I Raj. 16, 18 dan 19, dimana raja Ahab digambarkan sebagai suami atau laki-laki yang pasif sedangkan istrinya lebih banyak aktif dan mengambil inisiatif dalam menyelesaikan berbagai persoalan yang terjadi, mulai dari pembunuhan empat ratus nabi baal oleh Elia, ancaman pembunuhan terhadap Elia hingga pada upaya perampasan tanah milik Nabot. Konflik yang terjadi antara laki-laki dengan lakilaki ini, yaitu antara Ahab dan Elia, dan Ahab dan Nabot, berubah menjadi konflik antara laki-laki dengan perempuan, yaitu antara Elia dengan Izebel, dan Nabot dengan Izebel. Izebel mengambilalih apa yang seharusnya dilakukan oleh Ahab, suaminya.

Kisah dalam perikop I Raj.21:1-29 dimulai ketika Ahab meminta kebun anggur Nabot dengan cara menukarkan dengan kebun anggurnya, yang menurutnya lebih baik dari pada kebun anggur milik Nabot (tidak dijelaskan apa yang lebih baik itu). Jika Nabot tidak setuju dengan cara menukarkan kebun, Ahab memberikan sebuah tawaran untuk membayar dengan uang. Namun Nabot menolak untuk menjual kebun anggurnya kepada Ahab karena kebun tersebut merupakan warisan dari nenek moyangnya, yang diberikan oleh Tuhan kepada setiap keluarga atau klan di Israel. Ada aturan di Israel bahwa tanah adalah milik Tuhan, yang harus dipertahankan dan tidak boleh dijual (lih. 1 Raj. 8:36; Imamat 25: 23-28). Tanah juga berhubungan dengan identitas pemiliknya atau nama keluarga (bdk. Kisah anak-anak Zelafehad dalam Bil. 27:1-11). Ini berarti bahwa kehilangan tanah sama dengan kehilangan identitas dan menjual tanah sama artinya menjual harga diri. Tidak hanya itu, menjual tanah yang merupakan sumber kehidupan dari mana ia mendapatkan makanan, sama artinya dengan kehilangan hidup itu sendiri. Itulah sebabnya Nabot berani menentang perintah raja. Namun tidak demikian dengan Ahab, bagi Ahab tanah bisa diperjualbelikan, karena itu, ia berniat membelinya. ${ }^{24}$ Dengan demikian dapat dilihat bahwa ada sikap yang berbeda dalam

\footnotetext{
24 Asnath Niwa Natar, "Korupsi Yang Dilakukan Oleh Ahab dan Izebel dalam 1 Raj. 21:1-29", dalam Jurnal Sophia, No.1 Tahun 2016, p. 53.
} 
memandang tanah, yaitu sebagai warisan yang tidak boleh dijual, dan sebagai milik yang bisa diperjualbelikan. ${ }^{25}$ Sikap Ahab ini menunjukkan bahwa ia telah mengabaikan atau tidak menghormati tradisi nenek moyang dan agama yang dianut bangsa Israel. Ia juga tidak bisa menghargai hak milik rakyatnya, demi memenuhi ketamakannya. Sebagai seorang raja, ia seharusnya memberikan perlindungan, keadilan, dan kedamaian bagi rakyatnya, terutama mereka yang lemah, namun yang terjadi, justru ia sendiri yang merusaknya.

Oleh karena Nabot tidak bersedia memberikan kebun anggurnya, Ahab kecewa. Ia berbaring di tempat tidur, menelungkupkan mukanya dan tidak mau makan. Sikapnya ini kekanak-kanakan, mirip seperti anak kecil yang tidak mendapat mainan. Izebel lalu bertindak seperti "ibu" bagi Ahab (bdk. Sikap Debora sebagai "ibu" bagi Barak yang kekanakkanakkan). Ketika ia menemukan Ahab yang cemberut karena kebun Anggur Nabot, ia mengejek sekaligus menantang Ahab untuk menggunakan kekuasaannya, dengan mengatakan: bukankah engkau sekarang yang memegang kuasa raja atas Israel? Dengan kata lain, Ahab seharusnya bisa menggunakan kekuasaannya untuk mendapatkan apa yang ia inginkan.

Izebel kemudian berinisiatif untuk mengambil tanah Nabot dengan cara yang curang, yakni menggunakan kuasa kerajaan dengan cara menulis surat kepada tua-tua dan pemukapemuka kota atas nama Ahab. Penolakan Nabot dilihat oleh Izebel sebagai tindakan pembangkangan orang yang rendah dan lemah terhadap seorang penguasa. Nabot dipandang sebagai musuh negara. Ia lalu merancangkan kematian atas Nabot dengan tuduhan bahwa Nabot telah menghujat Tuhan dan raja yang adalah utusan Tuhan. Tindakannya ini kelihatannya legal dan tepat namun penuh dengan ketidakadilan. Nabot kemudian dirajam dengan batu dan mati. ${ }^{26}$

Izebel membunuh Nabot dengan cara yang licik. Ia tidak menggunakan tangannya sendiri sehingga seolah-olah ia tidak terlibat atas kematian Ahab. Namun Tuhan mengetahui semua yang dilakukan oleh Izebel dan karena itu akan menjatuhkan hukuman terhadap Ahab sekeluarga. Ahab sendiri tidak dihukum (I Raj.21:27-29) karena ia merendahkan diri di hadapan Allah, namun tidak demikian dengan istri dan anak-anaknya. Putranya Yoram dibunuh dan mayatnya dibuang ke kebun Nabot. Izebel sendiri mati dengan cara yang tragis, yaitu dibunuh dengan cara dijatuhkan dari jendela dan tubuhnya dimakan anjing (2 Raj. 9: 2237), sama seperti yang dinubuatkan oleh Elia. (1 Raj. 21:23-24). Allah menunjukkan keberpihakannya kepada rakyat kecil yang diperlakukan sewenang-wenang oleh penguasa. Hal ini menunjukkan bahwa seorang penguasa, atau raja sekali pun tidak bisa berlaku tidak adil dengan cara mengambil apa yang menjadi milik rakyat kecil yang lemah. Ada Tuhan sebagai pembela mereka.

Dari uraian di atas nampak bahwa pelaku utama dalam kematian Nabot adalah Izebel, seorang perempuan. Namun tanpa dukungan tua-tua, pemuka kota dan Ahab, yang semuanya

\footnotetext{
${ }^{25}$ Walter Brueggemann, 1 Kings, Atlanta, John Knox Press, 1982, p. 95.

${ }^{26}$ Asnath Niwa Natar, "Korupsi Yang Dilakukan.....p.54.
} 
adalah laki-laki, maka rencananya tidak akan berhasil. Lagi pula, sejak awal dikatakan bahwa Ahablah yang memiliki masalah namun diambilalih oleh Izebel untuk melindungi Ahab. ${ }^{27}$

Kesalahan Ahab adalah mengawini Izebel, seorang perempuan asing, menyembah berhala (ayat 25-26) dan merampas tanah milik Nabot. Dengan demikian, Ahab adalah pelaku utama kejahatan, yang kemudian juga mempengaruhi istrinya Izebel untuk melakukan kejahatan yang sama. Izebel menghalalkan segala cara, memanipulasi politik dan tidak mengerti sama sekali atau pura-pura tidak tahu tentang tradisi Israel mengenai tanah, demi memenuhi keinginan suaminya. Tanah milik rakyat kecil yang lemah diambil begitu saja oleh seorang penguasa dengan cara menyelewengkan kuasa yang ia miliki demi kepentingan pribadi. Akibatnya adalah mereka mati dengan cara yang sama seperti yang terjadi pada Nabot. Namun Izebel dipersalahkan atas tindakan ini.

Kendati demikian ada hal yang menarik dari Izebel. Ia dituntut untuk memenuhi perannya sebagai perempuan dalam budaya patriarkhi yaitu sebagai putri, istri dan ibu. Ia adalah putri dari raja Ethbaal, istri dari raja Ahab, dan ibu dari raja Joram. Karena relasinya dengan para lelaki ini, ia menunjukkan banyak pengaruh. Ia tidak hanya membawa ibadah baalnya ke Israel tetapi juga nabi-nabi baal. Ia tidak hanya mempengaruhi suaminya untuk menyembah baal, tetapi juga membunuh para nabi Yahweh. Sebagai seorang ratu, ia menggunakan pengaruhnya sehingga ia bisa membujuk Ahab untuk mengijinkan dia untuk mengambil kebun anggur Nabot. Untuk tujuan itu, ia mengambilalih nama dan materei raja (suaminya). Kematian Nabot juga dilaporkan kepada Izebel dan bukan kepada Ahab suaminya. Dengan ini, ia diakui sebagai figur yang punya kuasa dan berada di belakang raja Ahab. ${ }^{28}$

Dari sini dapat dilihat bahwa Izebel adalah seorang perempuan yang sangat percaya diri dan tahu apa yang harus ia lakukan, serta tidak takut untuk melakukan apa saja demi mencapai tujuannya. Izebel setidaknya memahami dirinya setara dengan Ahab. Ia berusaha mencapai apa yang Ahab tidak bisa capai. Aksesnya pada kekuasaan, secara khusus dalam budaya patriarkhi di Israel kuno, yang menyiratkan kontrol dan manipulasi laki-laki, namun ternyata oleh Izebel digunakan untuk mengontrol balik laki-laki, yaitu suaminya dan tuatua. $^{29}$

Dengan demikian nampak bahwa Izebel adalah seorang perempuan dan istri yang tidak diam, namun berani bersuara serta bertindak secara aktif di tengah budaya patriarkhi. Hanya saja tindakannya ini bukan pada dan untuk sesuatu yang baik, melainkan untuk sesuatu yang buruk.

\section{Kesimpulan}

Dari kisah Safira dan Izebel kita melihat bahwa kedua perempuan ini berada di bawah pengaruh budaya patriarkhi, namun yang satu berdiam diri, sedangkan yang lain bersuara dan

27 Ada dugaan bahwa tokoh Izebel bukan tokoh nyata, melainkan hanya digunakan sebagai metafor. Dugaan yang lain adalah bahwa kisah Izebel merupakan tambahan kemudian. Namun tentunya pandangan ini harus diteliti lebih jauh lagi. Lih. Claudia V. Camp, "1 and 2 King”, dalam: Carol A. Newsom and Sharon H. Ringe (Eds.), The Women's Bible Commentary, Louisville, Kentucky: Westminster/John Knox Press, 1992, p. 104.

${ }^{28}$ Alice L. Laffey, Wives, Harlots and Concubines. The Old Testament in Feminist Perspective, Philadelphia, Fortress Press, 1988, p. 130-131.

${ }^{29}$ Alice L. Laffey, Wives, Harlots .........p. 131. 
bertindak. Namun karena tindakan Izebel jahat maka nasibnya juga tidak jauh berbeda dengan Safira. Karena itu dibutuhkan sikap kritis dari kaum perempuan, untuk tidak diam saja ketika terjadi kejahatan, dan juga ketika bertindak agar tidak diarahkan kepada hal yang jahat. Ketidakmampuan bersikap kritis akan berdampak pada kematian. Seorang istri harus mampu bersuara dan menunjukkan sikapnya, berani memprotes bahkan melawan suaminya bila itu tidak benar. Perempuan atau istri berperan mengingatkan dan menegur suaminya bila melakukan kesalahan dan bukannya membiarkan atau malah ikut melakukan kesalahan yang sama.

\section{Referensi}

Aymer, Margaret., "Acts of the Apostles", dalam: Carol A. Newsom, Sharon H. Ringe and Jacqueline E. Lapsley (Eds.), Women's Bible Commentary, Revised and Updated, Philipphines: Claretian Communications Foundation, 2016

Asian Women's Resource Centre for Culture and Theology, Membaca Alkitab dengan Mata Baru, Yogyakarta, Asian Women's Resource Centre for Culture and Theology dan PERUATI, 2013

Atkinson, David, Rut, Jakarta, Yayasan Komunikasi Bina Kasih/OMF, 2000

Barth-Frommel, Marie Claire, Hati Allah Bagaikan Hati Seorang Ibu, Jakarta, BPK, 2003

Brueggemann, Walter, 1 Kings, Atlanta, John Knox Press, 1982

Camp, Claudia V., "1 and 2 King", dalam: Carol A. Newsom and Sharon H. Ringe (Eds.), The Women's Bible Commentary, Louisville, Kentucky: Westminster/John Knox Press, 1992

Grant, Robert M., Early Christianity and Society: Seven Studies, San Fransisco: Harper \& Row 1977

Hahn, Ferdinand, Theologie des Neuen Testaments. Bd. I: Die Vielfalt des Neuen Testaments, Tübingen: Mohr Siebeck, 2011.

Harrill, J. Albert, "Divine Judment Against Ananias and Sapphira (Acts 5:1-11): A Stock Scene of Perjury and Death", dalam Journal of Biblical Literature, Volume 130, No. 2, Summer 2011

Huda, Nur, "Melacak Akar Ketidakadilan Gender Dalam Islam. Telaah Terhadap Hadis Suwargo Nunut, Neroko Katut", dalam: Erwati Azis, dkk (Eds.), Relasi Jender dalam Islam, Surakarta, Pusat Studi Wanita STAIN, 2002

Keener, Craig S., Acts 3:1-14:28. An Exegetical Commentary, Volume 2, Grand Rapids Michigan: Baker Academic, 2013

King, Philip J., \& Lawrence E. Stager, Kehidupan Orang Israel Alkitabiah, Jakarta, BPK, 2012

Laffey, Alice L., Wives, Harlots and Concubines. The Old Testament in Feminist Perspective, Philadelphia, Fortress Press, 1988

Manurung, Nurseli Debora, "Kejujuran Sebagai Alat Melawan Korupsi (Kisah Para Rasul 5:1-11)", dalam Jurnal Sophia, No.1 Tahun 2016

Murniati, A. P., "Perempuan Indonesia dan Pola Ketergantungan", dalam: Budi Susanto, dkk (Eds.), Citra Wanita dan Kekuasaan (Jawa), Yogyakarta, Kanisius \& Lembaga Studi Realino, 1992

Natar, Asnath Niwa, "Korupsi Yang Dilakukan Oleh Ahab dan Izebel dalam 1 Raj. 21:1-29”, dalam Jurnal Sophia, No.1 Tahun 2016

Nugroho, H.B., "Perempuan Dalam Budaya Jawa", dalam: Jurnal Teologi Gema Duta Wacana, Ed.55 Tahun 1999 
Öhler, Markus, “Antikes Vereinswesen”, dalam: Klaus Scherberich (Ed.), Neues Testament und Antiken Kultur Band 2: Familie - Gesellschaft - Wirtschaft, Neukirchen-Vluyn: Neukirchener, 2011

Reimer,Ivoni Richter, "Die Apostelgeschichte. Aufbruch und Erinnerung, dalam: Luise Schottroff und Marie-Theres Wacker, Kompendium Feministische Bibelauslegung, Guetersloh: Guetersloher Verlagshaus, 2007

Schuessler Fiorenza, Elisabeth, Wisdom Ways. Introducing Feminist Biblical Interpretation, Maryknoll, New York, Orbis Books, 2001

Stueckelberger, Christoph, Corruption-Free Churches are Possible: Experiences, Values and Solutions, Globalethics.net Focus 2, Geneva, 2010

Trible, Phyllis, Texts of terror, Literary-feminist readings of biblical narratives, USA, SCM Press, 1992

Walby, Sylvia, Patriarki, Yogyakarta, Jalasutra, 2014

Walz, Heike, ....Nicht Mehr maenlich und weiblich...? Ekklesiologie und Geschlecht im Oekumenischen Horizont, Frankfurt a.M, Lembeck, 2006 